\title{
Cruzar fronteiras e construir a América do Sul: conexões entre Brasil e Argentina no final do século XIX
}

\author{
Laís Olivato ${ }^{1}$
}

PREUSS, Ori. Transnational South America: Experiences, Ideas, and Identities, 1860s1900s. New York, Routledge, 2016. 212 páginas.

\section{Resenha recebida em: $26 / 01 / 2018$ \\ Resenha aprovada em: 09/08/2018}

Transnational South America, de 2016, é o segundo livro publicado do historiador americanista Ori Preuss. Professor do Instituto de História e Cultura da Universidade de Tel-Aviv, Preuss estuda os intercâmbios transnacionais entre as capitais sul-americanas da passagem do século XIX para o XX. Trabalhando com fontes relacionadas ao fluxo de ideias e pessoas, o objetivo central dos trabalhos do autor tem sido analisar a formação histórica de um espaço denominado América Latina. Para isso, dialoga com o campo da História transnacional que, na última década, passou a questionar veementemente o conceito de Estado-nação como unidade de análise.

Imbricado na tarefa de construir categorias espaciais transnacionais cabíveis para a análise historiográfica, Preuss elegeu o processo de modernização do final do século XIX como o momento de intensificação das trocas entre os países então denominados latino-americanos. Seu grande desafio, contudo, é analisar a inserção do Brasil nesse espaço. Em Bridging the Island, publicado em 2011, o autor buscou percorrer a trajetória dos intelectuais que contribuíram para a formação de uma ideia de América Latina no

\footnotetext{
${ }^{1}$ Doutoranda em História Social na Faculdade de Filosofia, Letras e Ciências Humanas da Universidade de São Paulo. Realiza a pesquisa "Um projeto educacional nas Independências: A circulação do plano de ensino mútuo na América do Sul (1810-1830)", financiada pelo CNPq. e-mail para contato: laisolivato@gmail.com.
} 
Brasil. Já em Transnational South America, Preuss aumentou seu escopo ao propor um mapeamento da trajetória de ideias e pessoas que circularam entre o Rio de Janeiro e Buenos Aires com o intuito de fortalecer laços latino-americanos.

A tese dessa segunda obra parte do pressuposto segundo o qual a modernização na América do Sul teria criado espaços de trocas entre as cidades que permitiram novas maneiras de pensar projetos políticos e culturais em níveis nacional e regional. Conforme o autor, essas relações ocorreram principalmente de maneira horizontal na América do Sul, ideia frequentemente obscurecida pela historiografia que privilegia processos a partir de uma lógica "centro" e "periferia”, ou seja, Norte e Sul.

Preuss defende que existe uma identidade regional ibérica na América do Sul que a torna uma unidade cultural latina anterior à organização dos Estados-nação. A língua, que diferenciou as nações na Europa moderna, conectou as regiões na América do Sul. Porém, esse elo foi capaz de transpor barreiras linguísticas no período da modernização. Para o autor, o Brasil, tratado como uma exceção historiográfica, teve seu ponto de ligamento com esse universo cultural por meio de suas fronteiras no sul, que facilitaram o percurso de homens de letras no final do XIX.

Transnational South America parte do argumento de Angel Rama para contextualizar a "ciudad letrada" como um espaço combinado de intensa atividade educacional, diplomática e jornalística. Dessa ideia delineada pelo uruguaio, Preuss elege a diplomacia e o jornalismo como campos de análise. O estudo dos jornais é particularmente precioso para o historiador, pois em Buenos Aires há a maior quantidade de periódicos per capita do mundo nesse momento. Estima-se que em 1882, havia 224 periódicos para 3 milhões de habitantes na capital portenha. No Rio de Janeiro, o cenário não é diferente. Ambas são cidades portuárias e centros urbanos construídos com a idealização que envolvia sim Paris, mas com olhos para a realidade local.

Quanto à diplomacia, Preuss buscou reconstruir o fluxo de ideias latinoamericanas desse período por meio de trajetórias individuais. Assim, em uma tentativa de organizar as fontes impressas com percursos de diplomatas e políticos entre Rio de 
Janeiro e Buenos Aires, o autor dividiu o livro em quatro partes. No primeiro capítulo, Preuss privilegia o estudo da interligação entre textos em português e espanhol. No segundo capítulo, a ideia é enfatizar experiências pessoais de indivíduos que cruzaram fronteiras. O terceiro capítulo trata da diplomacia entre os dois universos. Por fim, o último capítulo aborda a construção da ideia de América Latina especialmente no Brasil.

De modo geral, são as trajetórias intelectuais que estruturam essa divisão. Em trânsito pela América do Sul, Vicente G. Quesada, Ernesto Quesada, Juan María Gutiérrez, Juana Manso, José Maria da Silva Paranhos, Carlos Guido y Spano, Juan Carlos Gómez, Bartolome Mitre, José Mármol, Quintino Bocaiúva, Estanislao Zeballos, D. Pedro II, Venancio Flores, Francisco Cunha, Hector Varela, Joaquim Nabuco, André Rebouças, Rui Barbosa, Miguel Cané, Ruben Darío, Roque Saénz Peña, Julio Roca, Eduardo Prado, Joaquim Francisco de Assis Brasileiro, Oliveira Lima, Luís María Drago e Carlos Rodríguez Larreta contribuíram para a formação de um fluxo de ideias em torno do debate sobre o sentido de ser latino-americano. Para percorrer os caminhos de seus atores, Preuss demonstra considerável erudição. Traduções, viagens, visitas públicas, conferências, imprensa, diplomacia cultural, intertextualidades, contatos pessoais e institucionais são apenas algumas das fontes para compreender contextos nacionais e regionais. Por esse motivo, na tentativa de construir um objeto transnacional, o autor atravessa múltiplos campos teóricos - como História Intelectual, História Diplomática, História Cultural, História Conectada -, o que torna suas análises, em alguns casos, desiguais.

Em seu primeiro capítulo, são as traduções que ganham destaque. Preuss parte dos estudos de Gustavo Sorá (2003), que apontam a prática da tradução como um experimento de alteridade. Dessa forma, o americanista descreve como as polêmicas que envolveram o governo de Juan Manuel de Rosas, a Guerra do Paraguai, a abolição da escravidão no Império brasileiro e a Proclamação da República brasileira foram retratadas nos jornais portenhos e cariocas. Para Preuss, a tradução colaborou para aproximar questões nacionais, brasileiras ou argentinas, de uma identidade coletiva. 
O caso da Guerra do Paraguai ajuda a compreender a inserção do Brasil nesse bloco. As opiniões sobre a única monarquia na América se dividiram nos textos do argentino Bartolomé Mitre e do uruguaio Juan Carlos Gómez. Este último via a guerra como uma cruzada liberal, enquanto o primeiro a entendia apenas como uma resposta a uma agressão. Foi por meio da entrada do jornalista argentino José Mármol que o debate foi apaziguado. Mármol afirmava que a Guerra havia permitido ao Brasil deixar a tradição imperial para trás e que uma nova geração de ideias surgiria a partir disso. Nos jornais brasileiros, apenas as cartas de Mitre foram traduzidas para o português. Na nota de Francisco Otaviano, responsável pela tradução, havia a observação de que na Argentina havia duas nações: uma civilizada localizada em Buenos Aires e outra semifeudal representada pelas províncias.

No segundo capítulo, as viagens ganham um papel importante na análise de Preuss. Comparada ao estudo das traduções, no entanto, as viagens como campo de estudos das trocas transnacionais na América do Sul é menos simétrica. Conforme o autor, o papel dos brasileiros foi mais ativo, pois viajaram mais. Aqui, Preuss nota que, diferentemente do apontado nos estudos de Mary Louise Pratt (2008) e Edward Said (2003), o relato de viagem nem sempre ocorre a partir de relações assimétricas, do centro para a periferia ou é determinado por uma "zona de contato". No caso da América do Sul de finais do XIX, o autor identifica que a viagem era utilizada como um recurso para interconectar e unificar culturas, ou seja, buscar semelhanças e não alteridades.

Para construir seu argumento, o autor se vale dos percursos de Quintino Bocaiúva, de Joaquim Nabuco, de Rui Barbosa e de André Rebouças no Rio da Prata. Os jornais brasileiros reproduziram artigos relacionados a tais visitas colaborando para criar a noção de "espaço trans-urbano unificado". Por outro lado, Preuss considera que a presença dos republicanos e/ou abolicionistas brasileiros na Argentina e no Uruguai teria colaborado para fortalecer a ideia de República em seu próprio país.

Os encontros entre diplomatas e presidentes é o objeto central de seu terceiro capítulo. Conforme o autor, a partir de 1890, a diplomacia pública conquista um novo 
espaço junto aos homens de letras. Além disso, a organização de conferências internacionais, as científicas ou as Pan-americanas, colaboram para facilitar encontros. Preuss destaca as trocas entre Rui Barbosa e Estanislao Zeballos como um passo dedicado à construção de uma América do Sul transnacional pautada na sociabilidade no e conhecimento.

Já em seu último capítulo, o autor preocupa-se com a imagem construída no Brasil e na Argentina sobre os Estados Unidos e a Europa. No Brasil republicano, um novo discurso anti-Ianque emergiu na virada do século com respaldo em artigos e textos de Eduardo Prato e de Joaquim Nabuco. Essa visão era concomitante a políticas de aproximação com a Argentina e com o Chile empreendidas por Joaquim Francisco de Assis, Rui Barbosa e Oliveira Lima. Nos discursos de Rui Barbosa, por exemplo, os países do Sul da América pertenciam à categoria de ordem, progresso e virilidade. Segundo Preuss, isso evidenciava que a construção dessa identidade diferia de visões “arielistas" também em voga no período. Para ele,

\footnotetext{
the interrelations between Europeanized Spanish-speaking and Portuguesespeaking Americans which are the main focus of this book - were much more equal, close, even intimate, than their interrelations with the north Atlantic center because of equal power, common enemies from the outside and inside, shared interests, culture and histories. (PREUSS, 2016, p. 158).
}

Assim, o autor conclui que enquanto o espaço latino-americano se formou a partir de conexões e semelhanças, suas relações com os países do Norte pressupunham distanciamento e alteridade, ao menos no âmbito do discurso. Transnational South America demonstra, portanto, que as aproximações entre o Brasil com seus vizinhos garantiram a construção de um espaço concreto de trocas atravessadas pela ideia de uma identidade latino-americana possível no final do século XIX.

Contudo, os argumentos de Preuss deixam algumas lacunas. A ênfase nas trocas horizontais e sua oposição à verticalidade no processo de modernização muitas vezes desconsidera a busca pela inserção da América do Sul no cenário hegemônico do Norte, 
tanto em termos culturais quanto político-econômicos. Muitos momentos descritos pelo autor, como os debates impressos sobre a Guerra do Paraguai, o discurso de Rui Barbosa na Conferência de Haya, a rápida visita de Roque-Saénz ao Rio de Janeiro, por exemplo, se comunicavam com os acontecimentos no Atlântico Norte. E, embora as relações horizontais existissem entre os vizinhos sul-americanos, o autor não analisa as mediações que ocorreram por meio do Atlântico Norte. Além disso, à exceção da Guerra do Paraguai, o autor não analisa se os conflitos econômicos e bélicos do final do século XIX, como a Guerra do Pacífico (1879-1883), em algum momento abalaram a constituição desse espaço de trocas sul-americanas.

Por fim, Transnational South America revela um esforço de fôlego ao mapear uma grande quantidade de fontes por meio de múltiplos pressupostos teóricos. Trata-se de um desafio que tem se revelado frequente entre os historiadores dedicados a análises transnacionais. O que tem se afirmado no trabalho de Ori Preuss é que as elasticidades colocadas nas delimitações geográficas de antigos objetos é um estímulo para a produção de novos olhares historiográficos. Pensar nas circulações de ideias e pessoas que ocorreram no espaço sul-americano nos ajuda a pensar a América Latina para além da construção de uma identidade imaginada.

\section{Referências Bibliograficas}

PRATT, Mary Louise. Imperial Eyes: Travel Writing and Transculturation. $2^{\text {nd }}$ ed. London: Routledge, 2008 [1992].

PREUSS, Ori. Transnational South America: Experiences, Ideas, and Identities, 1860s1900s. New York, Routledge, 2016.

. PREUSS, Ori. Bridging the Island: Brazilians' Views of Spanish America and Themselves 1865-1912. Madri: Iberoamericana, 2011.

RAMA, Ángel. The Lettered City. ed. And trans. John Charles Chasteen. Durham: Suke University Press, 1996. 
SAID, Edward W. Orientalism. London: Penguin Classic, 2003 [1978].

SORÁ, Gustavo. Traducir el Brasil: una antropología de la circulación internacional de ideas. Buenos Aires: Libres del Zorzal, 2003. 